\title{
Numerical simulation of damage in two-scale model of stainless steel 15-5PH
}

\author{
Tong Wu* - Philippe Gilles** — Michel Coret* \\ Alain Combescure* \\ * LaMCoS, INSA-Lyon \\ CNRS UMR5259, F-69621 Lyon \\ \{tong.wu, michel.coret, alain.combescure\}@insa-lyon.fr \\ ** AREVA-NP \\ F-92084 Paris La défense \\ philippe.gilles@areva.com
}

\begin{abstract}
This study concerns the modeling of the damage induced by a complex history of thermo-elasto-plastic multiphase in heat-affected-zone (HAZ) of welding. In this work, a twoscale model of elasto-plastic damaged multiphase is developed. The constitutive equations of the model are a coupling between the ductile damage, elasto-plastic deformations and phase transformation.

RÉSUMÉ. Ce travail concerne la modélisation de l'endommagement d'un matériau résultant d'une histoire complexe des déformations thermo-élasto-plastiques multiphasées subies par les zones affectées thermiquements. Un modèle mésoscopique élasto-plastique endommageable multiphasé est développé pour la transformation de phase. Les équations constitutives du modèle couplent l'endommagement ductile, les déformations élasto-viscoplastiques et la transformation de phase.

KEYWORDS: damage, welding, phase transformation, numerical simulation.

MOTS-CLÉS : endommagement, soudage, transformation de phase, simulation numérique.
\end{abstract}

DOI:10.3166/REMN.17.829-841 @ 2008 Lavoisier, Paris

REMN - 17/2008. Giens 2007, pages 829 to 841 


\section{Introduction}

Recently many efforts were devoted to the development of numerical models in order to predict residual stresses induced by hot process such as welding. Such prediction is difficult in multiphase, especially for phase transformation coupling with damage. Certain simulations took into account the volumetric change between $\alpha$ phase and $\gamma$ phase, and even transformation induced plasticity (Coret, 2002). Under certain conditions, welding operation damages material in some extreme cases. Consequently, our study herein concerns the modeling of the damage in phase transformation. In this work, a two-scale model of elastoplastic damage multiphase was developed in the framework of thermodynamics of irreversible processes. The constitutive equations are coupled with ductile damage, elastoplasticity, phase transformation, and transformation plasticity. The model employs a localizationhomogenization method to link internal variables in each phase and typical macroscopic variables. At the end of the article, an example of simulation of a disk heated by laser is given in order to illustrate the two-scale model applied in the martensitic stainless steel $15-5 \mathrm{PH}$.

\section{Material}

$15-5 \mathrm{PH}$ stainless steel is a martensitic precipitation hardening stainless steel offering high strength. The element compositions of 15-5PH (H1025), which is studied here, is shown in Table 1 . Welding of $15 \mathrm{Cr}-5 \mathrm{Ni}$ steel plays a significant role in the power and aeronautic industries. $15-5 \mathrm{PH}$ is quite different from austenitic stainless steel in that there are phase changes during heating and cooling stages. The mechanical properties of 15-5 PH are given in Table 2 and Figure 1.

Table 1. Chemical compositions of 15-5PH stainless steel (wt\%)

\begin{tabular}{ccccccccccccc}
\hline $\mathrm{C}$ & $\mathrm{SI}$ & $\mathrm{Mn}$ & $\mathrm{P}$ & $\mathrm{S}$ & $\mathrm{Cr}$ & $\mathrm{Mo}$ & $\mathrm{Ni}$ & $\mathrm{Cu}$ & $\mathrm{Al}$ & $\mathrm{N}$ & $\mathrm{NB}$ & $\mathrm{Fe}$ \\
.030 & 0.40 & 0.66 & .020 & .001 & 15.44 & .05 & 4.50 & 3.16 & .013 & .025 & .29 & balance \\
\hline
\end{tabular}

Table 2. Young's modulus and yield strength of 15-5PH

\begin{tabular}{ccccccc}
\hline \multicolumn{2}{c}{ Temperature $\left({ }^{\circ} \mathrm{C}\right)$} & 20 & 200 & 600 & 700 & 850 \\
\hline \multirow{2}{*}{ Martensite } & E (GPa) & 199 & 189 & 121 & 78 & - \\
& $0.2 \%$ SIG_Y $(\mathrm{MPa})$ & 1028 & 901 & 455 & 159 & - \\
\hline \multirow{2}{*}{ Austenite } & E (GPa) & - & 180 & 120 & - & 38 \\
& $0.2 \%$ SIG_Y (MPa) & - & 169 & 106 & - & 115 \\
\hline
\end{tabular}




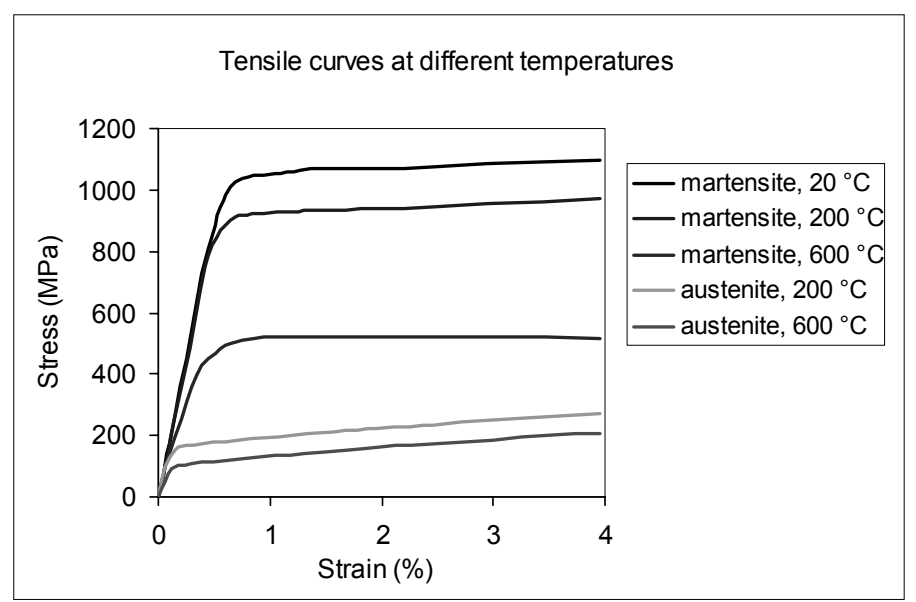

Figure 1. Tensile curves (strain vs. stress) of 15-5PH at various temperatures

\section{Definition of damage in two-scale model}

The article is limited to a two-phase model, and 1 represents martensitic phase and 2 refers to austenite. For martensitic stainless steel induced by welding, two phase transformations are included: $1 \rightarrow 2$ and $2 \rightarrow 1$. Volume fraction of martensite is $z_{1}$ and volume fraction of austenite is $z_{2}$. Then there is $z_{1}+z_{2}=1$.

Due to assumption of isotopic and homogeneous damage of ductile metal, the representative volume element (RVE) of two phases can be presented in 2-D. It is supposed that each phase has its own damage. The damage definition in two phases is shown in Figure 2.

The ductile damage variable $D$ is defined as the surface density of microvoids and microcracks in RVE.

$$
D=\frac{S_{D}}{S}
$$

where $S_{D}$ is the damaged surface and $S$ is total surface in RVE.

At microscopic scale, local damages occur in martensite and austenite. Accordingly the damage in phase $i$ at microscale can be defined by:

$$
D_{i}^{\mu}=\frac{d S_{D}^{i}}{d S_{i}} \quad(i=1,2)
$$


where $d S_{D}^{i}$ is the damaged surface in phase $i$ at microscale and $d S^{i}$ is total surface of phase $i$ at microscale.

The damage variable $D$ in Equation [1] can be divided into two parts: damage in phase 1 and damage in phase 2.

$$
D=\frac{S_{D}}{S}=\frac{S_{D}^{1}}{S}+\frac{S_{D}^{2}}{S}=\frac{1}{S} \int_{s^{1}} d S_{D}^{1}+\frac{1}{S} \int_{s^{2}} d S_{D}^{2}
$$

Introducing Equation [2] into Equation [3], there is:

$$
D=\frac{1}{S} \int_{s^{1}} D_{1}^{\mu} d S_{1}+\frac{1}{S} \int_{s^{2}} D_{2}^{\mu} d S_{2}
$$

Damage in phase $i$ is defined by:

$$
\begin{aligned}
& D_{i}=\frac{1}{S_{i}} \int_{S_{i}} D_{i}^{\mu} d S \quad(i=1,2) \\
& \xi_{i}=\frac{S_{i}}{S} \quad\left(i=1,2 \quad \xi_{1}+\xi_{2}=1\right)
\end{aligned}
$$

where $D_{i}$ represents average damage in phase $i$; $\xi_{i}$ is surface fraction of phase $i$.

Then

$$
D=D_{1} \xi_{1}+D_{2} \xi_{2}
$$

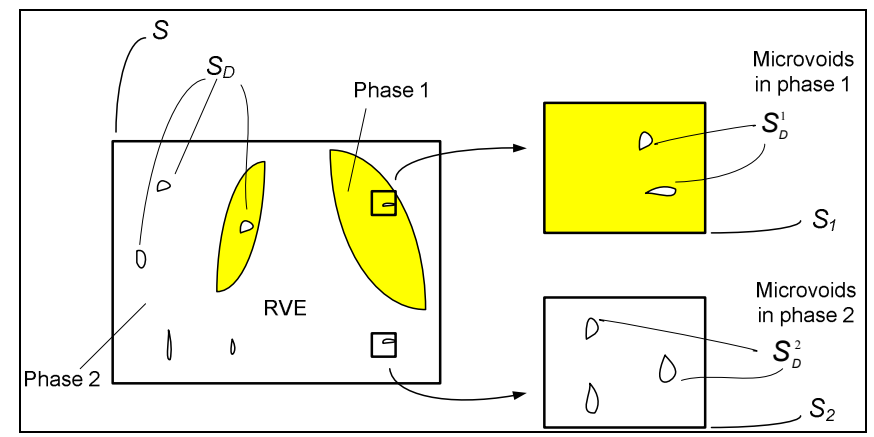

Figure 2. Definition of damage variables in RVE (Representative Volume Element) and in micro scale 


\section{Thermo-metallurgical problem}

In the study, it is supposed that mechanical and metallurgical behaviors have no influence on temperature, i.e. mechanical work generated heat and phase transformation induced latent heat are negligible. This leads to uncoupling of thermal and metallurgy-mechanical problem. Temperature $T$ at every point in the structure $\Omega$ is determined by the thermal characteristics and heat flux as well as other thermal boundary conditions. In the temperature calculation, the material is supposed to be homogeneous.

The calculation of austenite phase transformation (austenitization) can use the phenomenological model (see Equation [8]) proposed by (Leblond et al., 1984). For welding simulation of damage and stresses, its simple form at equilibrium state is used. For a slow heating rate, there is enough time to make the austenite fraction to reach equilibrium state for each temperature, and the austenite proportion is approximately linear with the temperature during phase transformation.

$$
\dot{z}_{1}=\frac{z_{e q}(T)-z_{1}}{\tau(T)}
$$

with $z_{\text {eq }}(T)$ for volumic proportion of phase in equilibrium and $\tau(T)$ for constant of time.

For martensitic phase transformation, Koistinen and Marburger's empirical law (Koistinen et al., 1959) can be applied to calculate the proportion of martensite. In the law, proportion of martensite is a function of temperature and austenite proportion.

$$
z_{1}=z_{2}\left(1-e^{-\beta<M_{s}-T>}\right)
$$

where $M_{s}$ is the martensite start temperature; $\beta$ is a coefficient which depends on material; $T$ represents temperature.

\section{A two-scale model of mechanical problem in multiphase}

A two-scale model is developed using the method of localization-homogenization. The homogenizing procedure used is the Taylor's approximation (Taylor, 1938), which assumes homogeneous strains in a heterogeneous medium with nonlinear behavior. This law provides the closest possible match with Leblond's theoretical case for elasto-plastic phases. Such approach, called micro-macro, consists of starting from the behavior of each phase and working back to the macroscopic behavior of the material. After localization, the behaviors of each phase can be 
treated respectively, without coupling. Thus, the model provides the freedom to choose the behavior type of each phase.

\subsection{Strain localization}

The approach of localization is based on the Taylor approximation with equal repartition of strain rates in all phases of the multiphase composites. The standard strain rate at macroscale is equal to total strain rate of single phase at microscale.

$$
\dot{E}^{c}=\dot{\varepsilon}_{i}(i=1,2)
$$

According to the principle of localization mentioned above, the total strain ratio is split into two parts, one coming from the total microscopic strain rate of the phases, and the other representing the plastic transformation strain rate.

$$
\begin{aligned}
& \dot{E}^{t o t}=\dot{E}^{c}+\dot{E}^{p t} \\
& \dot{E}^{t o t}=\dot{\varepsilon}_{i}+\dot{E}^{p t} \quad \forall i \quad \text { with } \dot{\varepsilon}_{1}=\dot{\varepsilon}_{2} \\
& \dot{\varepsilon}_{i}=\dot{\varepsilon}_{i}^{e}+\dot{\varepsilon}_{i}^{t h m}+\dot{\varepsilon}_{i}^{v p} \quad \forall i
\end{aligned}
$$

The transformation plasticity strain rate is guided by Leblond's transformation plasticity model (Leblond, 1989). A simplified form is as the following equation:

$$
\dot{E}^{p t}=\left\{\begin{array}{cll}
0 & \text { if } & z \leq 0.03 \\
-\frac{3 \Delta \varepsilon_{1-2}^{t h}}{\sigma_{\gamma}^{y}} \cdot \Sigma^{D} \cdot\left(\ln z_{2}\right) \cdot \dot{z}_{2} & \text { if } & z>0.03
\end{array}\right.
$$

where, $\Delta \varepsilon_{1-2}^{t h}$ is difference of thermal deformations between two phases, and $\sigma_{\gamma}^{y}$ is limited stress of phase of austenite. $\Sigma^{D}$ is deviator of the macroscopic stress.

After localization of strain, the problem of multiphase becomes the single phase behavior.

\subsection{Mechanical behaviors}

The elastic and thermo-metallurgical strains are

$$
\dot{\varepsilon}_{i}^{e}=H^{-1}(T) \underline{\sigma}_{i}+\left[\varepsilon_{i}^{t h m}(T)-\varepsilon_{i}^{t h m}\left(T_{r e f}\right)\right]
$$


with $\varepsilon_{i}^{t h m}=\alpha_{i}(T) \cdot T I$ for phase $1, \varepsilon_{i}^{t h m}=\alpha_{i}(T) \cdot T I-\left(1-z_{\gamma}\right) \Delta \varepsilon_{1-2}^{T_{\text {ref }}}$ for phase 2, $H_{i}=H_{i}^{0}\left(1-D_{i}\right)\left(H_{i}\right.$ is Hooke operator of phase $i, 0$ indicates initial state and $D_{i}$ is damage variable).

For the austenite, the elastoplastic model with linear kinematic work hardening is employed. As far as the 15-5PH stainless steel is concerned, it is supposed that damage in austenite is null $\left(D_{2}=0\right)$.

The yield function is:

$$
f_{2}=f_{2}\left(\underline{\sigma}_{2}, \underline{X}_{2}\right)=J_{2}\left(\underline{\sigma}_{2}-\underline{X}_{2}\right)-\sigma_{2}^{y} \leq 0
$$

The evolution laws are:

$$
\begin{aligned}
& \underline{\dot{\varepsilon}}_{2}^{p}=\frac{3}{2} \frac{\underline{\sigma}_{2}^{D}-\underline{X}_{2}^{D}}{J_{2}\left(\underline{\sigma}_{2}-\underline{X}_{2}\right)} \dot{p}_{2} \\
& \underline{X}_{2}=\frac{2}{3} C \underline{\dot{\varepsilon}}_{2}^{p}
\end{aligned}
$$

where $\underline{X}_{i}$ is kinematic strain hardening variable, $C$ is kinematic hardening parameter.

In terms of martensite, the elastoplastic model with isotropic hardening is chosen. The constitutive equations are coupled with damage variable of martensite $D_{1}$.

The yield function coupled with damage is given:

$$
f=f\left(\underline{\sigma}_{i}, R_{i}, D_{i}\right)=\frac{J_{2}\left(\underline{\sigma}_{i}\right)}{1-D}-\frac{R_{i}}{1-D}-\sigma_{y i}
$$

The evolution laws are obtained from the generalized normality law:

$$
\begin{aligned}
& \dot{\varepsilon}_{1}^{p}=\frac{3}{2} \frac{\dot{p}_{1}}{(1-D)} \frac{\underline{\sigma}_{1}^{D}}{J_{2}\left(\underline{\sigma}_{1}\right)} \\
& R_{1}=c_{1}(T)\left(1-D_{1}\right)\left[1-\exp \left(-\gamma_{1} p_{1}\right)\right]
\end{aligned}
$$

where $R_{i}$ is isotropic strain hardening variable, $c$ is isotropic hardening parameter.

The damage calculation chooses Lemaitre's ductile damage model (Lemaitre et al., 1994) as the following: 


$$
\dot{D}_{1}=\frac{D_{c r}}{\varepsilon_{c r}-\varepsilon_{t h}}\left[\frac{2}{3}(1+v)+3(1-2 v)\left(\frac{\sigma_{1}^{H}}{\sigma_{1}^{e q}}\right)\right] \dot{p}_{1}
$$

\subsection{Stress and damage homogenization}

The homogenized macroscopic stress is obtained by a linear law of mixture guided by the volume fraction of each phase. This simple homogenization could take stress at microscale back to macroscopic stress, which is involved in structure analyses.

$$
\sum=\sum_{i=1,2} z_{i} \underline{\sigma}_{i}
$$

The damage variable is defined and deduced from the surface fraction whereas the phase fraction is defined by the volume. The damage homogenization is given by the following equation:

$$
D=D_{1} \xi_{1}+D_{2} \xi_{2}=D_{1} z_{1}^{2 / 3}+D_{2}\left(1-z_{1}^{2 / 3}\right)
$$

\subsection{Memory effect during phase change}

The memory effect describes how internal variables in daughter phase inherit from mother phase when one phase (mother phase) disappears and the other phase (daughter phase) occurs. Memory coefficient determines how internal variables transfer from an old phase to a new phase. Herein, $\eta$ is memory coefficient of damage variable, $\mu_{i}$ is memory coefficient of internal variable $A_{i}$. The following equations give the relationship between internal variables in daughter phase and in mother phase:

$$
\begin{aligned}
& D^{\text {daughter }}=\eta \cdot D^{\text {mother }} \\
& A_{i}^{\text {daughter }}=\mu_{i} \cdot A_{i}^{\text {mother }}
\end{aligned}
$$

In the Equations 25 and 26, the memory effect is null if $\eta=0$ or $\mu=0$ and full if $\eta=1$ or $\mu=1$. 


\section{Numerical simulation}

In order to simplify the problem and focus on the metallurgical and mechanical analysis, an example of disk heated by laser will be provided (Figure 3). Compared the welding joint, the case of disk is applied to simulate the heat affected zone (HAZ) and base metal, and the molten weld part is neglected. In the section, the case of a disk heated by laser at center is simulated for the purpose of understanding and analyzing the damages and residual stresses produced during a welding operation.

For this disk simulation, the memory coefficient is supposed to be null $(\eta=0)$ because it is not easy to choose a specific value. The parameters of phase transformation and transformation plasticity models are given in Table 2. The parameters of damage model are shown in Table 4 . These parameters were identified in the lab. LaMCoS of INSA-Lyon in France.

Simulation of the disk heated by laser was implemented in software Cast3M. A disk made of $15-5 \mathrm{PH}$ with $160 \mathrm{~mm}$ in diameter and $5 \mathrm{~mm}$ in thickness, is heated at the centre by a spot laser for 70 seconds, then cooled by natural convection for 730 seconds. The mesh consists of 200 QUA4-type elements and the problem is considered as axisymmetric (Figure 4). The spot laser is modeled by a heat flux whose distribution on the upper side (Figure 5a). The lower and lateral sides are subjected to free convection. The coefficient of exchange convection is: $h_{c}=10 \mathrm{Wm}^{-2} \cdot{ }^{\circ} \mathrm{C}$. The radiation coefficient is expressed by $h_{r}=\sigma \varepsilon$, where the emissivity: $\varepsilon=0.7$ and the Helmotz constant: $\sigma=5.67 \times 10^{-8}$. The ambient temperature is supposed to be $20^{\circ} \mathrm{C}$.

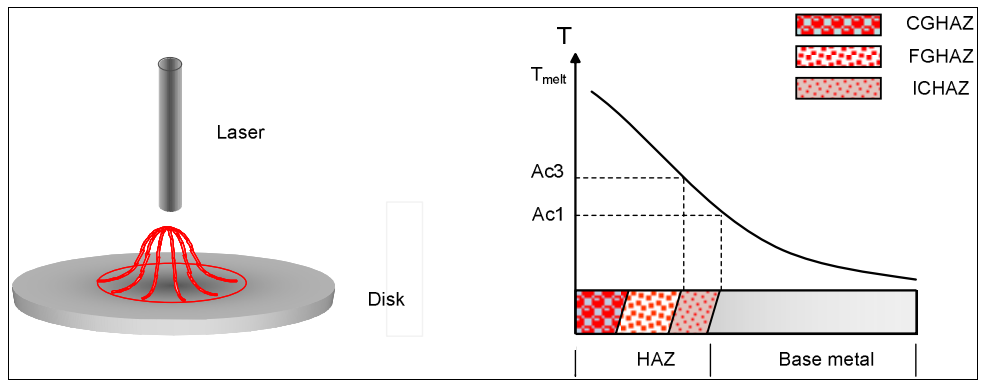

Figure 3. Schematic diagram of a laser heated disk and its $H A Z^{1}$

1. Coarse grained heat affected zone (CGHAZ): Tmax $>>$ Ac3. Fine grained heat affected zone (FGHAZ): Tmax is just above Ac3. Inter critical heat affected zone (ICHAZ): Ac1 < Tmax $<$ Ac3. 


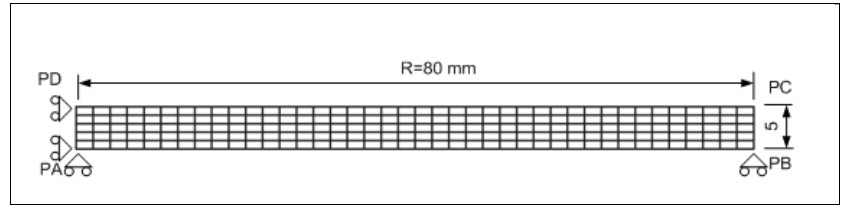

Figure 4. Mesh and dimensions of disk

Table 3. Parameters of phase transformation model

\begin{tabular}{cccccccc}
\hline Parameter & $M s$ & $A c 1$ & $A c 3$ & $\bar{\alpha}_{\alpha}$ & $\bar{\alpha}_{\gamma}$ & $\Delta \varepsilon_{1-2}^{\text {th }}$ & $\beta$ \\
Value & $160{ }^{\circ} \mathrm{C}$ & $760{ }^{\circ} \mathrm{C}$ & $820{ }^{\circ} \mathrm{C}$ & $1.25 \mathrm{E}-5$ & $2.09 \mathrm{E}-5$ & $9.58 \mathrm{E}-3$ & 0.011 \\
\hline
\end{tabular}

Table 4. Parameters of damage model

\begin{tabular}{|c|c|c|c|}
\hline Temperature & $\varepsilon_{t h}$ & $\varepsilon_{c r}$ & $D_{c r}$ \\
$20^{\circ} \mathrm{C}$ & 0.01 & 0.21 & 0.18 \\
$200^{\circ} \mathrm{C}$ & 0.01 & 0.20 & 0.07 \\
$600^{\circ} \mathrm{C}$ & 0.02 & 0.19 & 0.06 \\
\hline
\end{tabular}
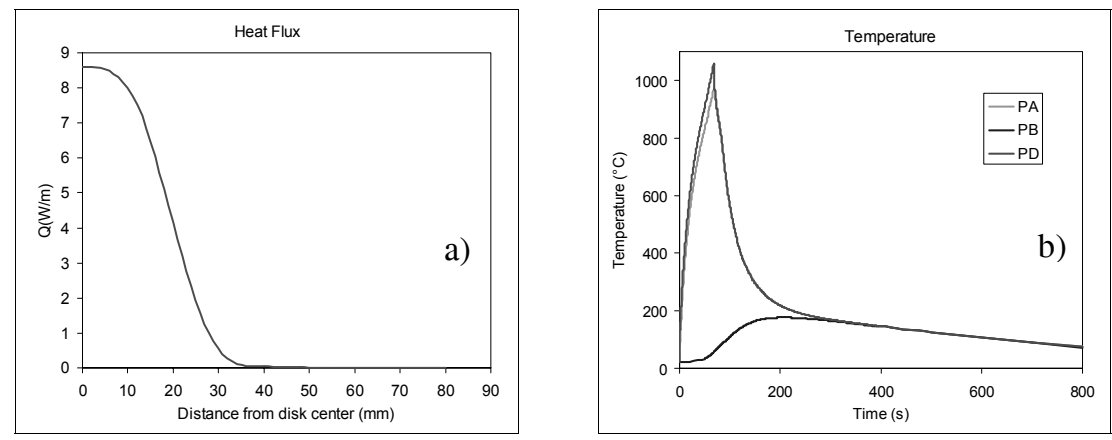

Figure 5. a) Flux input on upper surface of the disk, b) Temperature evolution on surface of the disk (Location " $P A$ " " $P B$ " " $P D$ ") 

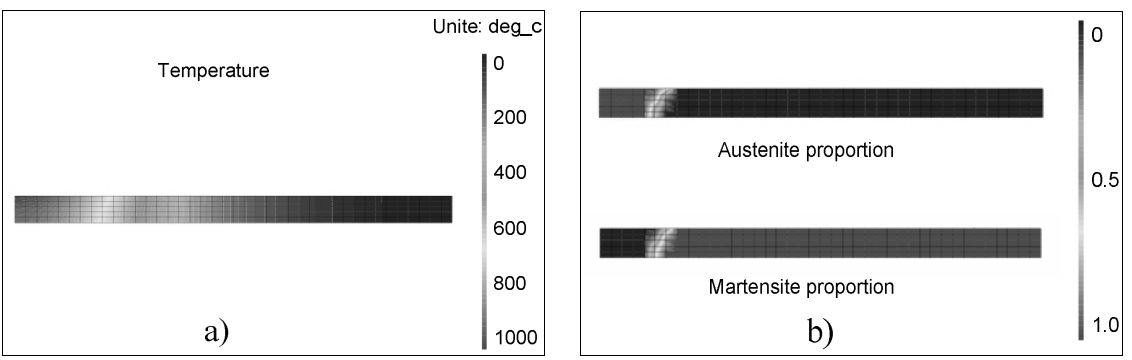

Figure 6. a) Temperature field at the end of heating (70 s), b) Phase proportion at the end of heating $(70 \mathrm{~s})$

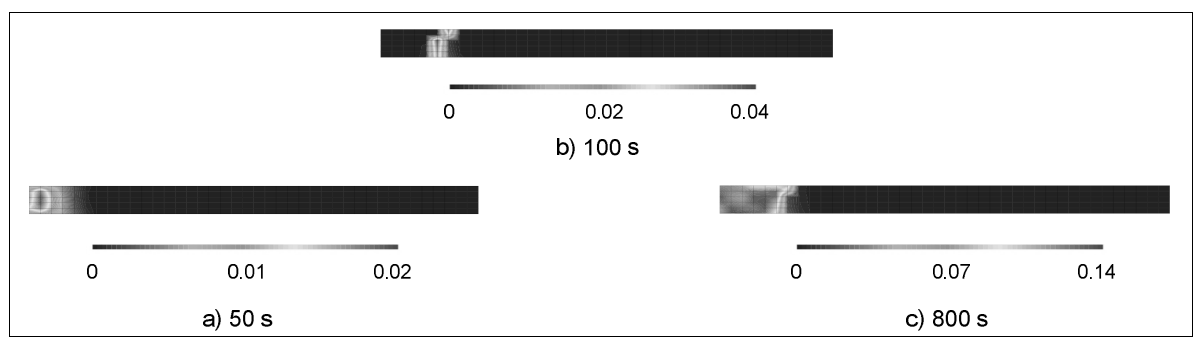

Figure 7. Damage field at 50 seconds (a), 100 seconds (b), at the end of cooling (c)

Temperature evolution at location "PA", "PB" and "PD" is shown in Figure $5 b$. The temperature field at the end of heating (70 s) is observed in Figure 6a. During the heating stage, the highest temperature reaches to $1050{ }^{\circ} \mathrm{C}$, and the temperature drops to $60{ }^{\circ} \mathrm{C}$ at the end of cooling. The initial (no thermal history) and final (after heating and then cooling) states material $15-5 \mathrm{PH}$ are supposed to be 100 percent martensitic. The phase proportion at the end of the heating stage $(70 \mathrm{~s})$ is plotted in Figure 6b. It shows that the phase at the center (CGHAZ and FGHAZ) is austenite and it is mixture of martensite and austenite at the ICHAZ.

The mechanical simulation used the previously calculated results: temperature and phase proportion. Transformation plasticity is coupled with mechanical condition. The time discretization can be different between the thermo-metallurgical and the mechanical calculations. The material properties are nonlinear with temperature, and experimental data at some specific temperatures (Figure 1, Table 2 and Table 4) are input in the program. Other values between the specific temperatures are linearly interpolated. 

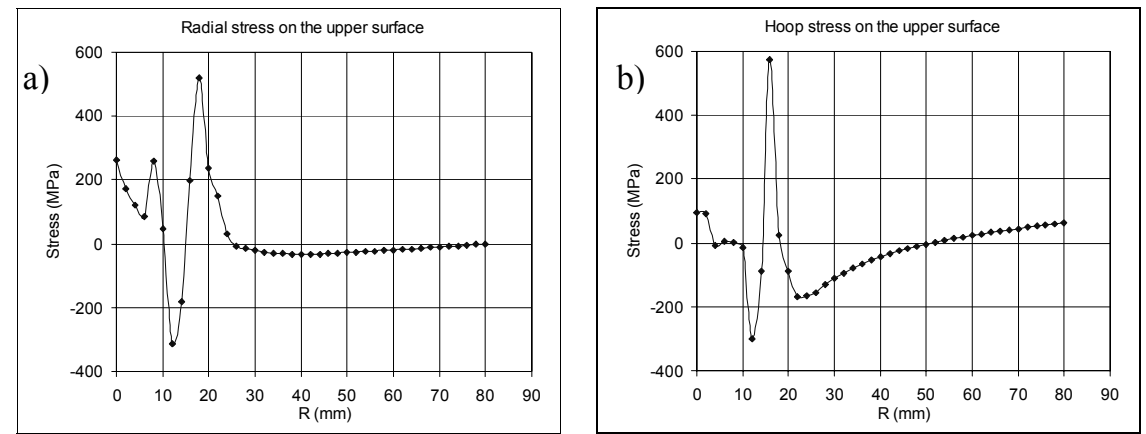

Figure 8. Residual radial stress (a) and hoop stress (b) on the upper surface of the disk

The damage was plotted at three representative moments: at 50 seconds when austenitic transformation does not happen (Figure 7a), at 100 seconds when austenite occurs at the centre of disk (Figure 7b), and at 800 seconds at which the martensitic transformation is completed (Figure 7c). The damage has happened before austenite occurred because of heating induced expansion at centre and restriction of surrounding cold metal. Even though the value of damage is very small, it indicated damage occurs firstly at centre. However, the damage was not observed at the centre in Figure $7 \mathrm{~b}$ because the central metal was changed into austenite and damage did not inherit from martensite due to a null memory coefficient $\eta$. At that moment, the damage appears on the boundary between martensite and austenite. When martensitic transformation is completed with the decreasing of temperature, the damage occurs and accumulates in the whole heat affected zone.

Stress and other internal variables are calculated by the proposed two-scale model. The peak residual stresses in radial or circumferential directions on upper surface of the disk are not at the center with highest temperature but at the ICHAZ region (Figure 8). The positive peak stress is at the ICHAZ, whereas the negative lies in FGHAZ near ICHAZ side.

\section{Conclusions}

The proposed model takes into account the thermal, metallurgical and mechanical phenomena which occur in the simulation of welding. Typically, the model focuses on the damage in phase transformation besides transformation plasticity. As far as the mechanical calculation is concerned, the two-scale model brings the freedom of choosing each material law. The model supports to trace history of each phase's behaviours (damage, stress, strain...). In the case of a heated disk, damage, phase fraction, stress and other internal variables are successfully simulated. 


\section{Acknowledgements}

This research is one part of project INZAT4 that devoted to study the behaviors of welding HAZ. INZAT4 is sponsored by EDF-SEPTEN, AREVA-NP, ESIGROUP and EADS-CCR. The models are implemented in the finite element software CAST3M ${ }^{\circledR}$ of CEA.

\section{Reference}

Coret M., Combescure A., "A mesomodel for the numerical simulation of the multiphasic behavior of materials under anisothermal loading", International Journal of Mechanical Sciences, Vol. 44, 2002, pp. 1947-1963.

Koistinen D.P., Marburger R.E., "A general equation prescribing extent ofaustenitemartensite transformation in pure Fe-C alloys and plain carbon steels", Acta Metallurgica, Vol. 7, 1959, pp. 59-60.

Leblond J.B., Devaux J.C., "A new kinetic model for anisothermal metallurgical transformations in steels including effects of austenite grain size", Acta Metall., Vol. 32 $\mathrm{n}^{\circ} 1,1984$, pp. 137-146.

Leblond J.B., Mottet G., Devaux J., Devaux J.C., "Mathematical models of transformation plasticity in steels", International Journal of Plasticity, Vol. 5, 1989, pp. 573-591.

Lemaitre J., Chaboche J.L., Mechanics of Materials, Cambridge University Press, Cambridge, 1994.

Taylor GI., "Plastic strains in metals", Journal of the Institute of Metals, Vol. 62, 1938, p. $307-24$. 
